\title{
Erratum zu: Kommentar zum Mietrecht
}

\section{J. Herrlein et al. (Hrsg.), Kommentar zum Mietrecht, https://doi.org/10.1007/978-3-662-56074-7}

Nachfolgende Fehler wurden korrigiert:

1. Vorwort

Die Jahreszahl im Vorwort wurde von 2021 zu 2020 korrigiert.

2. Bearbeiterverzeichnis

Die Schreibweise des Namens des Bearbeiters Heiko Ormanschick wurde korrigiert (statt Ormanschik).

3. Kommentierung der mietrechtlichen Vorschriften des WiStG

Der Titel der Kommentierung zu $§ 6 \mathrm{WiStG}$ wurde korrigiert (statt $§ 6 \mathrm{WiSG}$ ).

4. Autorennamen auf SpringerLink

Aufgrund eines technischen Fehlers wurden auf SpringerLink irrtümlicherweise die Herausgebernamen statt der Bearbeiternamen bei den Kommentierungen der einzelnen Vorschriften angezeigt. Dies wurde korrigiert.

Der Verlag bittet, diese Fehler zu entschuldigen.

Die aktualisierte Fassung ist abrufbar unter:

https://doi.org/10.1007/978-3-662-56074-7

(C) Springer-Verlag GmbH Deutschland, ein Teil von Springer Nature 2021

E1

J. Herrlein et al. (Hrsg.), Kommentar zum Mietrecht,

https://doi.org/10.1007/978-3-662-56074-7_126 